\title{
Scabies of the child: Epidemiological, clinical, therapeutic and evolutionary aspects in the service of Dermatology of the Regional Hospital of Thiès (Senegal): About 69 cases (2012-2017)
}

\section{Haby Dione ${ }^{1,2}$, Pauline Diousse ${ }^{1,3}$, Agbogbenkou Tévi Déla-dem Lawson ${ }^{1,4}$, Mariama Bammo ${ }^{1,3}$, Mame Diasse Ndiaye', Pape Souleymane Toure', Fatou Seck', Ndeye Ramatoulaye Diagne Gueye1, Sylvie Audrey Diop1, Bernard Marcel Diop1, Mamadou Mourtalla $\mathrm{Ka}^{1}$}

${ }^{1}$ Faculty of Health Sciences, University of Thiès, Thiès, Senegal, ${ }^{2}$ Department of Dermatology, Hospital Abdou Aziz Sy Dabakh, Tivaouane, Senegal, ${ }^{3}$ Department of Dermatology, Thiès Regional Hospital, Thiès, Senegal, ${ }^{4}$ Department of Infectious and Tropical diseases, Hospital Abdou Aziz Sy Dabakh, Tivaouane, Senegal

Corresponding author: Dr. Haby Dione, E-mail: habydione@hotmail.com

\begin{abstract}
Background: Clinical manifestations of scabies in children differ from those of adults: difference accentuated by the presence of certain contributing factors which contributes to delayed diagnosis and management. The objective of our study was to study the epidemiological, clinical, therapeutic and evolutionary aspects of scabies in children. Materials and Methods: From January 1st, 2012 to December 31st, 2017, a descriptive retrospective study was conducted in the dermatology department of the Regional Hospital Center of Thiès. The study included records of children aged 0 to 15 years in outpatient care. The data was entered and analyzed using a computer with Epi info7 software version 3.5.4. Results: Of the 19129 patients seen in consultation, 2284 were children, of whom 69 had scabies, with a hospital prevalence of $0.36 \%$. The average age was 4.64 years and the sex ratio were 1.46 . Out-of-school children predominated with $47.8 \%$. Mothers were out of school in $79.71 \%$. Voluntary cosmetic depigmentation was practiced by $65.22 \%$ of mothers. The average consultation time was 21.86 days, pruritus was present in $56.5 \%$ of cases. Topography with interdigital spaces predominated in $81.15 \%$ of cases. All the children had been treated with benzyl benzoate. The cure rate was $92.7 \%$. The complications were bacterial superinfection in $60.87 \%$ of cases, eczema in $4.34 \%$ and acute glomerulonephritis in $1.44 \%$ of cases. Conclusion: Scabies of the child is still relevant. Its prevalence and complications make it a real health problem and can be life-threatening in children. The main objective remains prevention.
\end{abstract}

Key words: Scabies; Child; Thies; Senegal

\section{INTRODUCTION}

Human scabies is an Ectoparasitosis, contagious, common caused by the female of a mite of the species Sarcoptes scabiei variety hominis. It's a cosmopolitan disease. It has been recognized since 2013 by the World Health Organization (WHO) as a neglected tropical disease. Its worldwide incidence is about 300 million new cases per year, with prevalence up to $10 \%$ of the general population and $60 \%$ of children in poor communities [1]. In industrialized countries, epidemic episodes mainly affect institutions (retirement homes, care institutions, communities, etc.) In developing countries, the prevalence and complications of scabies,

\footnotetext{
How to cite this article: Dione H, Diousse P, Lawson ATD, Bammo M, Ndiaye MD, Toure PS, Seck F, Gueye NRD, Diop SA, Diop BM, Ka MM. Scabies of the child: Epidemiological, clinical, therapeutic and evolutionary aspects in the service of Dermatology of the Regional Hospital of Thiès (Senegal): About 69 cases (2012-2017). Our Dermatol Online. 2020;11(2):135-139.

Submission: 26.11.2019; Acceptance: 02.02.2020

DOI: 10.7241 /ourd.20202.4
} 
especially in the pediatric population, make them a real public health problem [2].

In Senegal, few studies have been conducted on scabies $[3,4]$. In the region of Thiès, no study has been carried out, which justifies our work whose objectives were to determine the epidemiological, clinical, therapeutic and evolutionary aspects and to identify the factors that favor scabies in children and mother in the dermatology department of the regional hospital of Thiès.

\section{MATERIALS AND METHODS}

This was a descriptive and analytical retrospective study, conducted over a period of 05 years, from January 1, 2012 to December 31, 2017 in the dermatology department of the Thiès Regional Hospital. Included in the study were all records of children aged 0 to 15 years in the outpatient department of dermatology for scabies. Patients with confounding pathology isolated or associated with scabies such as atopic dermatitis, contact dermatitis, prurigo, infantile Acropustulosis have been excluded. Epidemiological, clinical, therapeutic and evolutionary data were collected using a standardized survey form. The analysis of the epidemiological data was carried out using the software Epi info version 3.5.4 of July 30, 2012 of the CDCAtlanta (USA). The analytical data were expressed with a risk of error $\alpha<5 \%$.

\section{Ethics Statement}

This study was performed on records of patients.

\section{RESULTS}

Sixty-nine cases of children between the ages of 0 and 15 years with scabies were collected, with a hospital prevalence of $0.36 \%$ among 19129 consultants including 2284 children. Scabies among children were more common in the second half of the year, peaking at $14 \%$ in October. The median age was 4 years and the mean age was 4.6 years a standard deviation of 4.13 and the 2- to 15-year age group was the most represented with 37 cases. The sex ratio H/F was 1.46. Twenty-nine infants were under breastfeeding.

Thirty-three children were out of school and 12 children, or $17.4 \%$ of the children, attended Koranic school. Forty-three children came from a semi-urban area, fourteen children came from a rural area and twelve children from an urban area. The practice of voluntary cosmetic depigmentation was more common among mothers of infants aged 1-24 months More than $3 / 4$ mothers were out of school $(79.71 \%)$ and the practice of voluntary cosmetic depigmentation was more common in this group (Table 1). Most of the mothers were housewives, or $88.40 \%$. In $63.77 \%(\mathrm{~N}=44)$ of the cases, the number of people living in the same house was between 7 to 10 people and the number of people affected in the patient's entourage averaged 2.05. The average consultation time was 21.8 days \pm 18.9 days and extremes ranging from 3 to 120 days. The meantime to view was longer for children whose

Table 1: Distribution of the level of schooling of mothers according to the practice of VCD

\begin{tabular}{lccccccc}
\hline Mother Education & \multicolumn{4}{c}{ DCV } & Total & P value \\
\cline { 2 - 3 } & \multicolumn{2}{c}{ Yes } & \multicolumn{2}{c}{ No } & & \\
\cline { 2 - 3 } & N & $\%$ & & N & $\%$ & & \\
\hline No Education & 35 & 63.6 & & 20 & 36.4 & 55 & 0.759 \\
Primary & 4 & 80.0 & & 1 & 20.0 & 5 & \\
Secondary & 6 & 66.7 & & 3 & 33.3 & 9 & \\
\hline
\end{tabular}

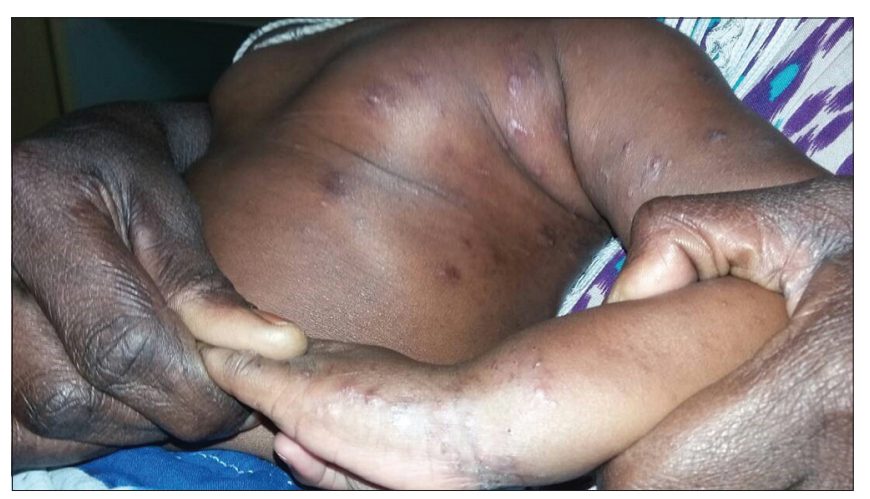

Figure 1: Papular lesions of the outer edge of the hand and wrist in an infant.

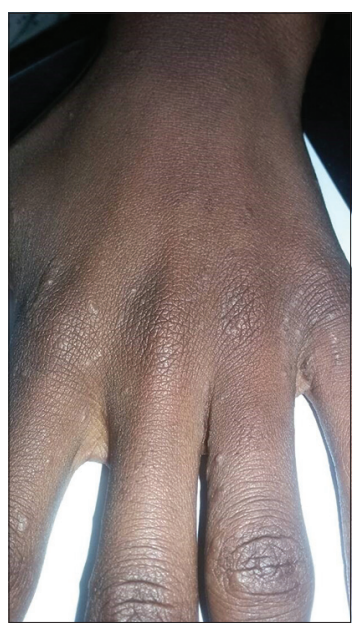

Figure 2: Furrows on the back of the hand next to the joints in a child. 
mothers practiced VCD 18.8 days \pm 9.7 compared to those who did not practice $16.8 \pm 6.2$ ).

Pruritus was present in $56.5 \%(\mathrm{~N}=39)$ of children. The most frequent lesions were papules found in $88.4 \%$ of cases (Fig. 1) followed by grooves that were present in $20.3 \%$ of patients (Fig. 2) and then by vesicles present in $10.14 \%$ of cases: In 42 children or $60.86 \%$ coexisted crusted lesions. The location of lesions in interdigital spaces was the most common with $81.15 \%$ of cases. Palmar plantar location was more common in infants with $43.47 \%$ of cases $(\mathrm{N}=29)$. Therapeutically, benzyl benzoate was used in all children. The combination benzyl benzoate, antiseptic, antibiotic and antihistamine was the most prescribed at $81.15 \%$. More than $3 / 4$ of the patients' family members, $79.71 \%(\mathrm{~N}=55)$, received treatment with benzyl benzoate. A treatment of their environment by the use of a disinfectant (Malathion) has been recommended in all our patients. The mean duration of follow-up was 27.16 days $+/-12.15$ (extremities 10 to 75 days). Almost all children, $92.7 \%(\mathrm{~N}=64)$ had a favorable course of treatment and $7.3 \%$ of children $(\mathrm{N}=5)$ had a recurrence. Forty-six patients, 66.66\% $(\mathrm{N}=46)$ had complications. It was essentially bacterial superinfection in $60.87 \%$ of cases of eczema in $4.34 \%$ of cases and acute glomerulonephritis in $1.44 \%$ of cases.

\section{DISCUSSION}

In our study, the hospital prevalence of scabies was $0.36 \%$. It was below that found by Niang and al in Koranic schools in Dakar with 23.33\% [3]. This high prevalence would likely be related to the fact that the study was conducted in a community where skin contact was tight and prolonged. This same tendency was objectified by Kouotou and al in Cameroon (17.8\%) who had conducted his study in a boarding school [5]. In a dermatology department in Guinea, scabies ranks second in the study of infectious dermatoses in children [6]. Indeed, the prevalence varies according to the work. A frequency peak has been noted in winter. [7].

A study done in Dakar found a greater frequency during the harmattan period (hot and dry continental trade winds of West and Central Africa) [8]. The increase in promiscuity and the decrease in body care during this period could also explain this high frequency. However, we noted a greater frequency during periods of high play activity: in June with $12 \%$ of cases, July $12 \%$ of cases and October $14 \%$ of cases. In our study, the average age was 4.6 years. A high infestation rate of scabies in preschool children has also been found in some studies, particularly in the Central African Republic and northern England [9,10]. The male predominance found in our series, as well as those of Kouotou et al [5] and Sherbiny et al [11] would probably be due to prolonged contact at the time of the games but also to the exchange of clothes.

In our series scabies was more common among children living in a large family. Our results are consistent with those of the El Sherbiny et al series in Egypt as well as that of Niang et al in Dakar [3-11]. The role of voluntary cosmetic depigmentation (CVD) in the occurrence of scabies has already been described by several authors. For example, in Mauritania and Senegal scabies has been described in women practicing DCV $[12,13]$. The increase in promiscuity and the decrease in body care during this period could also explain this high frequency. However, we noted a greater frequency during periods of high play activity: in June with $12 \%$ of cases, July $12 \%$ of cases and October $14 \%$ of cases.

In our study, the average age was 4.6 years. A high infestation rate of scabies in preschool children has also been found in some studies, particularly in the Central African Republic and northern England [9,10]. The male predominance found in our series, as well as those of Kouotou and al [5] also Sherbiny and al [11] would probably be connect to prolonged contact at the time of the games but also to the exchange of clothes. In our series scabies was more common among children living in a large family. Our results are consistent with those of the El Sherbiny and al series in Egypt as well as that of Niang and al in Dakar [3-11]. The role of voluntary cosmetic depigmentation (VCD) in the occurrence of scabies has already been described by several authors. For example, in Mauritania and Senegal scabies has been described in women practicing VCD $[12,13]$.

In our series, VCD was more practiced by mothers of infants, uneducated. Maternal education and occupation had an impact on the occurrence of scabies in children. A study in Turkey found that infestation was more common among children whose mothers were housewives than among educated and employed mothers [14]. In our study, the delay in diagnosis was related to the delay in consultation which was up to 120 days. The latter also depended on the level of education of the mother. The specific signs of scabies most commonly observed in our study were papules; 
present in $89.18 \%$ of cases. In contrast, in Bangui, scabious nodules were more observed (64.1\%) [9].

The scabious grooves difficult to demonstrate on phototype VI were present in $20.3 \%$ of cases in our study and in $76 \%$ of cases in a French study [15]. The classical topography of scab lesions in interdigital spaces was noted in $81.15 \%$ of our children. The particular location of lesions in the axillary and palmoplantar zones in infants was found in $44.92 \%$ of cases in our series and was correlated with the practice of voluntary cosmetic depigmentation in the mother with a statistically significant difference. This depigmentation used for a long time, would lead to local immunosuppression increasing the risk of infection, promoting contamination which would partly explain the large number of people with the environment.

Therapeutically, benzyl benzoate (Ascabiol $\left.{ }^{\circledR}\right)$ is the standard treatment in France [16].

In our series, the $\mathrm{BB}$ was the most prescribed because of its cost, its availability, the absence of major contraindications with a favorable evolution in $96 \%$. Our results are similar to those of Ly and al in Senegal, which showed that BB was significantly more effective than ivermectin, whereas it was prescribed as first-line therapy in other mostly European studies $[11,17]$.

In our study, approximately $3 / 4$ cases of family members of patients had received anti scabious treatment. This incomplete management of the surroundings and the environment could partly explain the long follow-up period for children by probable recontamination.

On the other hand, our results showed that the practice of VCD in the mother would increase the duration of evolution of scabies. This duration may interfere with the occurrence of complications. On the evolutionary level, in our series the evolution was favorable in $92.7 \%$ of the cases. However, complications such as eczema, impetigo and post-streptococcal acute glomerulonephritis have been noted. Eczema can complicate scabies either from the beginning in case of a history of eczema or after treatment and may be due to intolerance to the products used. Impetigo is the most common complication.

Data from suggest that in highly endemic areas, at least $40 \%$ of impetigo lesions can be attributed to scabies [18-20].
Post-streptococcal acute glomerulonephritis is the most feared complication in developing countries. Although it is low in our series, a study done in Dakar by Dieng and al had collected in a pediatric ward a proportion of $56.6 \%$ acute glomerulonephritis on mange [21].

\section{CONCLUSION}

Scabies is a neglected, cosmopolitan tropical disease. It is still relevant. Its prevalence and its complications especially in the pediatric population, make it a real health problem. The management of scabies of infants and children raises unique challenges. The main contributing factors are precariousness, promiscuity, lack of hygiene. Others, such as the low level of education of mothers, delayed care, voluntary cosmetic depigmentation, have been reported in the literature, responsible for profuse forms in most cases.

\section{Statement of Human and Animal Rights}

All procedures followed were in accordance with the ethical standards of the responsible committee on human experimentation (institutional and national) and with the Helsinki Declaration of 1975, as revised in 2008.

\section{Statement of Informed Consent}

Informed consent was obtained from all patients for being included in the study.

\section{REFERENCES}

1. World Health Organization. Water, sanitation and health: Waterrelated diseases, Scabies. 2001. Accessed 9/2/18 Available from: $<$ http://www.who.int/water_sanitation_health/diseases/scabies>.

2. Hay RJ, AC Steer, Engelman D, Walton S. Scabies in the developing world-its prevalence, complications, and management. Clin Microbiol Infect. 2012;18:313-23.

3. Niang SO, Dieng MT, Kane A, Diallo M, and al. the prevalence of dermatoses in Koranic schools in Dakar (Senegal). J Mali Med. 2008;23:6-9.

4. Sarcoptes scabiei. ADW. Accessed 10/6/19. Available at: https:// animaldiversity.org/accounts/Sarcoptes_scabiei/classification/

5. Kouotou EA, Komguem MK, Bissek ACZK. Prevalence and determinants of human scabies in schools: the case of Cameroonian boarding schools. Ann Dermatol Venerteol. 2015;14:627.

6. Tounkara TM, Soumah MM, Keita M, Diané B. Profil épidémiologique et clinique des dermatoses infectieuses chez les enfants au service de dermatologie de l'hôpital national Donka. Ann Dermatol Venereol. 2012;139:137-8.

7. Mimouni D, Ankol OE, Davidovich N. Seasonality trends of scabies in a young adult population: a 20 year follow up. Br J Dermatol. 2003;149:157-9.

8. Ben Maiz H, Ben Moussa F, Goucha R, Abderrahim E, Kheder A. Acute postinfectious glomerulonephritis. Nephrol Ther. 2006;2:93-105. 
9. Kobangué L, Guéréndo P, Abéyé J, Namdito P, Mballa MD, Gresenguet G. Gale sarcoptique: aspects épidémiologiques, cliniques et thérapeutiques à Bangui. Bull Pathol Exot. 2014;107:10-4.

10. Church RE, Knowleden J. Scabies in Sheffield: a family infestation. Br Med J. 1978;1:761-3.

11. Naglaa A, El Sherbiny, Talal A, Hassan M, Hassan NS, Zeiada AN. Epidemiological Study of Scabies in Primary Schools, Fayoum Governorate- Egypt. J Prim Health Care Gen Pract. 2017;1:1-5.

12. Mahe A, Ly F, Aymard G, Dangou JM. Skin diseases associated with the cosmetic use of bleaching products in women from Dakar, Senegal. Br J Dermatol. 2003;148:493-500.

13. Kebe M, Yahya S, Lo B, M. Ball. Study of complications of artificial depigmentation in Nouakchott, Mauritania. Mali Medical. 2015;3:38-40.

14. Ciftci IH, Karaca S, Dogru O, Cetinkaya Z, Kulac M. Prevalence of pediculosis and scabies in preschool nursery children of Afyon, Turkey. Korean J Parasitol. 2006;44:95-8.

15. Pouessel G, Dumortier J, Lagrée M, Pierre MH, Ganga-Zandzou PS, Ythier $\mathrm{H}$, et al. Scabies: a common infection in pediatrics. Pediat Arch. 2012;19:1259-60.

16. Royer M, CM Latre, Paul C, Mazereeuw-Hautier J. The French Society of Pediatric Dermatology, "Infant scabies". Ann Dermatol Venerteol. 2008;135:876-81.
17. Brooks PA, Grace RF. Ivermectin is better than benzyl benzoate for children scabies in developing countries. J Paediatr Child H. 2002;38:401-4.

18. Aung PTZ, Cuningham W, Hwang K, Andrews RM, Carapetis JR, Kearns T, et al. Australian Aboriginals: A self-controlled case series study. PLoS Negl Trop Dis. 2018;12:6668.

19. Mason DS, Marks M, Sokana O, Solomon AW, Mabey DC, Romani L, et al. The prevalence of scabies and impetigo in the Solomon Islands: A population-based survey. PLoS Negl Trop Dis. 2016;10:4803.

20. Romani L, AC Steer, Whitfeld MJ, Kaldor JM. Prevalence of scabies and impetigo worldwide: A systematic review. Lancet Infect Dis. 2015;15:960-7.

21. Dieng MT, Ndiaye B, Ndiaye AM. Scabies complicated by acute glomerulonephritis in children: 114 cases observed in two years in a pediatric ward in Dakar. Dakar Med. 1998;43:201-4.

Copyright by Haby Dione, et al. This is an open-access article distributed under the terms of the Creative Commons Attribution License, which permits unrestricted use, distribution, and reproduction in any medium, provided the original author and source are credited.

Source of Support: Nil, Conflict of Interest: None declared. 